\title{
Racism, eh? Interactions of South Asian Students with Mainstream Faculty in a Predominantly White Canadian University ${ }^{1}$
}

\section{EDITH SAMUEL \& SHEHLA BURNEY}

Atlantic Baptist University \& Queen's University

\section{ABSTRACT}

Considerations of the interactions between minority students and mainstream faculty in academe have only partially portrayed the enigma of racism. Through this qualitative study of twenty-two SouthAsian-students in a predominantly white Canadian university, we investigate how discourses of racism are categorically produced and performed through power relations, notions of ethnicity, negative images and stereotypes that acquire ideological significance in the ivory tower. We argue that both overt and covert racism, more than a mere representation of tension and two solitudes is programmed in the powerful postmodern/postcolonial discourse of the culture of the "Other". As practiced in the current teaching and learning environment, it seems that differential treatment, inequity, and negligence are perceived in the daily interactions between minority students and mainstream faculty, affecting overall evaluations, grading, tracking, and teaching styles. This analytical inquiry recommends that a critical mass of professors from visible minority and designated groups is needed to address these negative perceptions, leading to a wholesome academic environment. 


\section{RÉSUMÉ}

Des perspectives reconnues et vraisemblables à l'égard de l'interaction, en milieu universitaire, entre les étudiants minoritaires et le professeur régulier, ne dépeignent que partiellement l'énigme que constitue le racisme. Dans cette étude qualitative, comprenant vingtdeux étudiants originaires du sud de l'Asie qui se trouvent dans une université canadienne à prédominance blanche, nous examinons comment le discours du racisme apparaît de façon systématique dans les relations de pouvoir et dans les notions d'ethnicité, d'images négatives et de stéréotypes qui acquièrent une signification idéologique dans la tour d'ivoire. Nous soutenons que le racisme, aussi bien manifeste que voilé, plus qu'une simple représentation d'une tension et de deux solitudes, est programmé dans le puissant discours post-moderne / post-colonial de la culture de l'autre. Actuellement, dans le milieu universitaire, il semble que le traitement différentiel, les inégalités et la négligence sont clairement perceptibles dans les interactions quotidiennes entre étudiants minoritaires et professeur régulier et que, dans l'ensemble, cela affecte les évaluations, la notation, la répartition des étudiants par niveau, ainsi que la façon d'enseigner. Notre étude estime qu'il est grandement nécessaire que bon nombre de professeurs appartenant à des minorités visibles et à des groupes ciblés travaillent à modifier ces perceptions négatives et à créer un environnement universitaire plus sain.

\section{INTRODUCTION}

At the turn of the century, a ground-breaking study on the hiring of visible minorities at Canadian Universities made front page headlines in The Toronto Star, a leading Canadian newspaper: " $U$ of $T$ faculty: Where minorities not very visible" (Rushowy, 2000). This was one of those rare occasions when the world of academe hits the street to become part of everyday discourse. Dr. Chandrakant Shah, an award-winning professor who has been at the University of Toronto since 1972 had launched a study of diversity after realizing that he and another professor, both scheduled to retire in 2003 , were the only two members of visible minorities out of 28 professors in the department of Public Health Sciences. Dr. Shah's 
statistical study found that hypothetically, even if an average of $15 \%$ of all new faculty members hired by the University of Toronto were visible minorities, it would take more than 25 years before the minority complement represented $15 \%$ of the professoriate. The figures that Shah used were not based on a quota system. Instead, he used a mathematical model of probability that assumed the university fills an average of $15 \%$ of all job openings with a visible minority candidate, in a faculty population of 1,710 and an annual rate of new hires of $5 \%$ (or 85 job openings). Shah commented: "When I first saw the numbers...I shook my head and said, 'It can't be, it can't be true.' " These findings revealed the paucity of faculty positions held by members of so-called visible minorities - a designated group under the Federal Contractors' Program. ${ }^{2}$ Nothing much has changed in the last three years. At Queen's University, for example, the number of visible minorities in 2003 stands at $8.7 \%$. The University of Toronto has not fared much better.

The low percentage of visible minorities among full-time faculty is common at Canadian universities with the exception of one department at the Ontario Institute for Studies in Education of the University of Toronto where half of the professors hail from visible minority groups. In most universities, the proportion is below $10 \%$. While the multiethnic, multilingual and multiracial population of Canada continues to grow rapidly, and though visible minorities are projected to become the majority (Statistics Canada, 1996), the University workplace does not reflect this diversity. Moreover, despite the changing face of Canada, the core curriculum continues to be mainly Eurocentric, traditional and Western, representing mainstream Canada.

The lack of role-models from diverse cultures, the exclusions of history, literature and culture of the "Other" that exclude half the knowledge of the "World" (Said, 1983), the hegemonic representations of what Said calls "Orientalism," the omissions of race, class, gender and the third world in media and texts, make the question of racism and postcolonial discourse, identity and pedagogy, highly problematic (Giroux, 1992; Spivak, 1990). In the light of these issues, the necessity of hiring academics from diverse minorities is a priority. 
The university is a place of learning. The learning environment is generally expected to provide students with positive and productive experiences. Apart from acquiring 'knowledge,' students are eager to explore new avenues of social interaction, intercultural understanding, and international insights (Hall, Kulig, Thorpe \& Pfeuti, 1998). Faculty are in a preferential and privileged position to influence the classroom atmosphere and to create environments where students learn effectively and successfully. Bock (1997) affirms that "faculty play an important role in influencing the overall campus climate and in creating a culture conducive to learning" (p. 7).

The process of learning means acquiring critical thinking skills, and a sense of social responsibility (Giroux, 1992; Pushkin \& ColonGonzalez, 1998). Moreover, "success" implies good academic grades or skills that lead to professional positions in what Stanley Aronowitz (2000) calls "the knowledge factory" - the present-day corporate university structure (p. 3). In this social context, it is imperative that students and professors relate to each other through cultural, personal and intellectual interaction as the professor is a role model who is able to influence learning, thinking, acting, and doing.

Culture and language are key issues that shape the framework of learning. Jenkins (1983) argues that faculty-student communication patterns are sometimes hampered by problems of stereotyping, biases in language structure and usage and discriminatory epithets in classroom interaction that can differentially affect students of diverse backgrounds. Professors' cultural and personal backgrounds influence the mode in which critical thinking skills are facilitated and the manner in which male and female students interact (p. 1). Thus, for students of colour, the learning process can be obstructed or hampered by faculty members' bias, ideology, stereotyping and a sheer lack of knowledge of the "Other." As Pushkin and Colon-Gonzalez (1998) point out, racism can hinder the personal growth and the cognitive maturation of students of colour (p. 16). Again, Dei, Mazzuca, Mclsaac and Zine (1997) note:

For many of the students, negative experiences of school were related to differential and unjust treatment at school. This treatment was most strongly and most frequently related to 
issues of race. Examples of such treatment involved teacherstudent relationships. (p. 78)

\section{THE STUDY}

To understand perceptions of racial bias in a Canadian university, we conducted a study of 22 second-generation South Asian students ${ }^{3}$ in a predominantly white university in Ontario. This inquiry uses interview data collected from the 22 students to examine teaching styles, evaluation criteria and students' personal experiences and perceptions.

Perceptions are integral to evaluation and assessment and reveal the innermost thoughts of students. Perceptions (images/words) are semiotic codes by which we make external forms of attitudes, ideas and discourse (Sperber \& Wilson, 1986). Seeing leads to knowing and cognition is influenced by collective experience and cultural difference. A sign is a cultural artifact, its meaning is mediated by culture and context (Burney, $1989,2002)$. Thus perceptions are forms of signifiers that reveal symbolic meaning for those who share the meaning of the sign. They are a form of tacit knowledge, which cannot be proved overtly but which highlights the hidden curriculum entrenched in outward structures. Perceptions are emotive responses which spring up intuitively.

Thus, perceptions are mediated through shared meaning. As Foucault (1973) says, a sign operates only through "shared knowledge," and the possibility of substitution between two elements: "it can be constituted only by an act of knowing" (pp. 46-77). There is no "mute" sign. The perceptions of students reported in this study are indicative of discrimination, which the students interpretted as "racism." Racism is perceived and experienced viscerally on intuitive, emotional and subtle planes. Gestures, tone, attitude, language, which might be construed as "neutral" by the mainstream, ${ }^{4}$ are not necessarily so, but are embedded with shared meanings stemming from shared understandings and interpretations.

It is important to note that all the 22 students interviewed, interpreted certain attitudes and responses of professors as being coloured by racist overtones. The phenomenon of racism is not necessarily seen as systemic and structural by these students but is interpreted on a personal 
level. In their minds, there was no doubt that their racial/ethnocultural difference had contributed to differential treatment and led to negative experiences of isolation and exclusion. Whether racism exists cannot be proved categorically. However, it needs to be taken seriously as a distinct possibility based on the perceptions of these ethnic-origin students.

While several studies have focussed on white mainstream students or black minority students in higher education, this is one of the few studies of minority students who hail from a South Asian background. However, this is not a comparative study. It focuses on the South Asian students' perceptions of their interaction with faculty, most of whom are white, mainstream members. Hegemonic power relations (Foucault, 1980) define all interactions between faculty and students. However, power relations that operate between different racial groups can systemically be interpreted as indicative of racist structures.

A lack of a comparative method may be interpreted as a limitation of the study, as we have not interviewed South Asian professors and their interaction and relationship to mainstream students nor have we interviewed mainstream faculty's interaction with minority students. We feel that such comparisons, in this context, are not equal or equitable as minority faculty do not form a "dominant" group like the white mainstream faculty. The power relations described by South Asian students between faculty/students cannot be applied or ascribed or translated into a similar discourse between mainstream students and mainstream faculty. Thus, the necessity of interviewing South Asian minority professors and mainstream students does not become an issue because of the miniscule numbers of minority faculty and an entirely different power dynamic that this situation creates.

The perceptions of South Asian students in this study, pointed unequivocally toward perceptions of racism based on differential treatment because of their race, colour and ethnicity, and cultural difference. Despite the fact that overt allegations of racism were not made, students cited stereotyping, (what they called "labeling") as one of the most common factors that influenced faculty evaluation, everyday interaction, classroom teaching, and general discourse. This study, in short, reveals the absolute necessity of filling in the gaps and inequities in academia, 
curriculum, and pedagogy by hiring more minority faculty who are representative of the demographic characteristics of Canadian society and in a manner consistent with Canadian Multiculturalism policy.

\section{METHODOLOGY}

The research process was complemented by criterion-based selection of the participants (Moon, Dhillon \& Sprenkle, 1990) and the sampling strategy of snowballing (Marshall \& Rossman, 1999). The sampling strategy of snowballing or chain method is a process of people referring information-rich key informants to the researchers. The criteria for the participants included (a) South Asian identification ${ }^{5}$ and (b) completion of two years of university attendance. Willingness to participate in the study was a decisive factor in respondent selection. Twenty-two students (10 males and 12 females) who were born in Canada or had accompanied parents who had migrated to Canada as children from India, Pakistan, Bangladesh and Sri Lanka generally between 1970-1990 were interviewed "as complex, diverse and communicating subjects" (Maclear, 1994, p. 71). To represent a cross-section of disciplines, students from Law (4), Engineering (4), Medicine (2), Computer science (4) Science (4) and Arts (4) were selected. Each participant was interviewed for about an hour and a half. The subjects ranged in age from 22 to 65 years.

Two open-ended, semi-structured questions were asked: (a) How would you describe your relationship with mainstream faculty members? and (b) How did these experiences contribute to the existence of racism in the educational process with particular reference to teaching styles, grading, and 'tracking'?

Participants were initially contacted through the presidents of the South Asian Students' Associations on the university campus. Interested students were contacted by telephone to (a) provide participants with a brief description of the study (b) request their participation in the study and (c) ensure their appropriateness for the study. An appointment for the interview was scheduled at that time. Qualitative research legitimacy (Marshall \& Rossman, 1999) was conserved by (a) tape-recording and detailed note-taking of interviewees' responses, (b) a content-analysis of 
the responses (c) use of participants' verbatim quotes for valid responses and meanings and (d) linking the research findings to theoretical perspectives and empirical studies about the prevalence of racism in faculty-student relationships.

The method of analysis of data was conducted at two levels - first, analyzing the personal accounts of the students - what was said, how it was said and why it was said. Second, applying sociological and critical constructs to the personal accounts - to analyze why students had those experiences in the light of relevant theories, assumptions and premises. Specifically, the data analysis was carried out in relation to systemic factors that deeply influenced South Asian experiences such as race, class, gender, culture, and immigration.

Data analysis involved transcribing the taped interviews and conducting a content analysis on each of the interviews. As well, personal notes were added on each of the interviewees regarding mannerisms, body language of any sort and general comments on the tone of the interview. Each transcribed interview was numbered. Student files were coded on the basis of gender, age, department and academic standing. Verbatim quotes that were forceful, persuasive and convincing were highlighted and marked off for referencing. In this way, certain themes and patterns were drawn out and highlighted. For example, certain responses such as the need for hiring more minority faculty, enrollment of more minority students and implementing an anti-racist curriculum were consistent themes drawn from the interview sessions.

Names of departments are masked or not used at all to ensure that subjects could not be identified. The name of the university has been unidentified.

\section{ANALYSIS OF FINDINGS}

In this study all $(100 \%)$ of the twenty-two interviewed students claimed that they had experiences of what they interpreted as racism with some faculty members who were unsympathetic and unwilling to give them support and encouragement. The data from this study indicates that positive relations with faculty have constructive, encouraging 
and affirming experiences for minority students, while negative reactions from faculty can cause much angst, torment and distress, leaving them vulnerable, exposed, defenseless, and helpless in an alienated university milieu. Negative reactions of faculty can also have detrimental, harmful and damaging effects on academic performance, emotional well being and the personal choices of South Asian students. For example, negative interactions, such as stereotyping, are perceived to affect students' academic performance and "can result in limited aspirations and restricted choices for women and men from different cultural backgrounds" (Jenkins, 1983, p. 4).

Stereotyping refers to race, class, gender, and ethnicity as social constructs of groups and to the gross generalizations of simplistic and often inaccurate assessment of group behaviour. Stereotypes, in this category, may be "positive" when Asians are seen as belonging to the "model minority stereotype"6 or "negative" when Black students are perceived as being dull and dense. The term "model minority" originated in the United States and has been used and critically questioned more recently in the Canadian context (Razack, 1995, p. 76). Canadian scholars (Maclear, 1994; Mukherjee, 1992) have used the term to mean that "Asians" excel academically "due to certain cultural traits" (Razack, 1995, p. 76). Marcias (1993) disagrees with the "cultural trait" premise and argues that the social construction of the "model minority" stereotype is associated with the "the histories of colonialism," denoting that all Asian groups do not excel academically.

It is possible that in some instances both positive and negative stereotypes function to hamper academic success. When the "model minority stereotype" is applied positively, the pressure to succeed is so great, that sometimes minority students are not able to rise to the high standards expected of them. Stereotypes operate negatively when some minority students who are assumed to be stupid and unintelligent perform poorly in academic work. As a result, both positive and negative stereotypes can work negatively to hamper academic success in minority students. For instance, the following four South Asian students, two from the Sciences and the other two from the Arts, in this study, recount 
positive and negative aspects of stereotyping with regard to academic excellence:

1. I also have the intellectual self-confidence that I know that I am better than my white counterparts in studies. With regard to academic achievement, the professor also expects a high standard from me. $^{7}$

2. Due to intense competition, I have to excel academically and measure up with other intelligent students. Professors in the sciences require a better performance from me than from my white peers.

3. Professors tend to stereotype you as belonging to one particular cultural background, that is, a person of colour and expect a certain level of academic work from you. Even if you have done well, they [faculty members] still feel that the work does not come up to the class standard.

4. This professor thought that our presentation in an Arts subject was not good enough, even though the rest of the class did not think so. He held the stereotypical view that no matter how we presented, it was not up to the 'standard.'

These four students narrate both positive and negative effects of stereotyping causing academic stress in their lives. The first two students in the Sciences expressed the notion that they had "intellectual self-confidence" and had to "measure up" and that they were academically on par or even better than their white peers. They also asserted that the professor "expected a high standard" of academic work from them and that they faced pressure to rise up to faculty expectations. In these cases, the students seem to conform to the stereotype that minority students performed well in mathematics and science (Razack, 1995). It is also possible that these students tried to excel in academic work due to parental pressure and their minority status.

The third and fourth students in the Arts professed that due to their minority status and to differences in cultural background and skin colour they were "expected" to acquire a low level of achievement in academic work (Maclear, 1994; Mukherjee, 1992). The stereotype that Asian students excelled only in mathematics and the sciences is exemplified. This 
stereotype often applies to South Asian students also. Cindy Lam (1996), a racial minority teacher of Chinese origin depicts her experience with the Metropolitan Toronto school system. Initially, she was a teacher of core-French but had to switch to ESL (English as a second language) teaching due to "negative experiences related to stereotyping and racism in her core-French assignments" (Lam, 1996, p. 18). The stereotype demonstrated in her case was that it was "inappropriate" for her to teach "pure" language courses such as core-French and that she was "more suited" to instruct ESL classes.

These stereotypes, both positive and negative are misleading and inaccurate and are socially constructed in media representation and replicated in course content and educational texts. Further, there is evidence to suggest that educators rely on social theorists who use questionable methods to measure minority groups' achievement levels and attitudes (Margolis \& Romero, 1998).

The second use of stereotyping is when gross generalizations of group behaviour are attributed to individuals (Margolis \& Romero; 1998). Stuart Hall (1997) explains this aspect of stereotyping as "signifying racial difference" (p. 244). Drawing from the colonial experience of slavery, Hall asserts that the subjugated status and "innate laziness" of blacks were "natural" and characteristic of "innate primitivism, simplicity and lack of culture" (p. 244). Describing this aspect of racialized representation, cultures of black people have been "reduced" to "nature or naturalizing difference" (p. 245). The reasoning that underlies the process of naturalization entails that if differences are "cultural" they can be changed but if they are "natural," they are fixed or permanent. Hall (1997) affirms: "Naturalization is therefore a representational strategy designed to fix 'difference,' and thus secure it forever" (p. 245). Stereotyping is, therefore, "reducing" group behaviour to signifiers of a few essential characteristics, "fixed by nature"(p. 245). Individuals are misjudged regarding their abilities and actions when elements or signifiers of group characteristics are functionally applied to them. There were some students who narrated experiences of this kind. One female student relates: 
I am evaluated inaccurately in my academic work. Even though my essays are analytical, professors say that there is a lack of analytical thinking and that there needs to be more coherence in the correlation of ideas. I feel that they unduly try to find fault with my work. They seem to conform to the group stereotype that South Asian students cannot think and write on their own.

This student had the perception that she was misjudged in her abilities and capabilities, because of stereotyping. Stereotyping is a form of racist labeling which according to Margolis and Romero (1998), is a "strong form of the hidden curriculum" (p. 2). Claude Steele (1997) argues that when minority students are reduced to the level of a negative typecast they experience "stereotype threat" as the label hangs "like a threat in the air." Consequently, these negative attitudes can hinder a student's intellectual and academic performance.

Describing racist experiences as being a part of the "hidden curriculum," an Arts student observed that a professor was deliberately impolite to her and that he did not care whether or not she did well in her courses. He seemed to believe in the "cooling out" process or the "socialization process that encourages students to lower their expectations and to identify situations they once protested as 'normal' and unchangeable" (Young, 1974, cited in Margolis \& Ramero, 1998). "Cooling out" is a way of redirecting students to what is assumed to be more realistic alternatives rather than having them fail the courses. The following student was made to realize that as a South Asian and a female student she could not do well in mathematics. In her words:

There was one math course. Before our first test, I had done all the questions in the book ahead of time. So I asked him for additional questions. That professor had some reference textbooks (not available in the library) and I could have photocopied the questions and answers in ten minutes. But he said abruptly that he could not give me the additional questions. I ended up getting a low mark. He didn't care about my marks and did not want me to do well. He thought I couldn't do well in math - which is not true because I got $86 \%$ later on in another math course. 
In this student's case, although the professor did not directly say that the student could not do well in mathematics, his action in not giving her the additional questions indicated that he may have had lowered expectations about the competence of the minority student or that he did not want to be bothered. This gesture was interpreted by the student as negative and racist. The uncaring and unsupportive attitude of the professor made the student perceive that he was exhibiting racist and sexist behaviour regarding her ability to excel in mathematics.

Carl James (1997) explains that some minority students, due to their earlier educational experiences lack confidence and anticipate differential treatment, racism and discrimination in university settings. One student in this study was forceful about the existence of racism exhibited by unaccommodating faculty on campus.

I have experienced overt racism in school and expected it here in this place [university]. Just because I don't see it [racism] it doesn't mean that it's not there. I find it difficult to know because things are not overt. I cannot make a definitive statement about it. I could have experienced it. Certain profs have been supportive - here I don't find most of them that supportive in guiding you in your academic work. This really affects my confidence level.

That this student was not able to easily detect and discern racism in the attitude of some of the professors led him to perceive discrimination in a hidden and subtle manner viscerally and psychologically. This is indeed a common experience as covert racist attitudes are hard to pinpoint. He also relayed the notion that he was confused about receiving mixed messages from faculty members and said that at university, mainstream faculty had been unsupportive. This is a form of intangible racism.

Minority students, generally feel that racism and discrimination are structural/systemic phenomena that are embedded in historical ideology (Marcias, 1993), socially constructing students of colour as possible underachievers or as less intelligent. Some faculty are perceived to instill negativity in South Asian students' thinking about their own "potential." The following two students recall this experience of constant discouragement. 
1. I am an economics student, but I am not allowed to take a business course. You have to constantly argue with them. Sometimes, low expectations are set for people of colour and somehow they [faculty] feel that you may not come up to the standard.

2. One professor told me that I had to work harder to be in this class. I don't think I should be made to feel that way. I feel I am judged on the basis of my colour by the way I am looked at and spoken to. That affects me and makes me feel miserable.

These students express the perception that by being forced to think about their own potential as being substandard, minority students are underrated and made to feel that they do not come up to the class standard. Subjects also expressed the notion that they had to "constantly argue" with the professors to express their points of view and be understood. The fact that all of the above students felt the need to constantly assert themselves is indicative of a deep discontent stemming from perceived racist attitudes and stereotyping.

Some professors, however, were perceived as being overtly racist in their attitudes and behaviour towards South Asian students. Huffman (1991) reported that "subjective feelings of racism among [minority] students stemmed from derogatory oral remarks about [minorities] in general and verbal attacks directed at specific individuals" (Brown \& Kurpius, 1997, p. 4). A professor in the faculty of medicine was perceived to have made derogatory and cynical remarks about a student of colour:

This professor always made racist remarks about the way I dressed and my looks and said when we were doing medical clinical skills development that "it is hard to see the spots on my skin because I was dark." Even though I spoke to the professor about it, she continues to make those remarks.

This student recalled an example of overt racism when she described the incident. She perceived this mainstream professor as being callous and inconsiderate of the feelings of students of colour and asserted that she continued to maintain negative attitudes. These negative attitudes can affect students - diminish their interest in learning, affect their clinical 
and academic performance, lower their self-esteem and impact future aspirations and goals.

Some dominant professors also were perceived to display biases in regard to language structure and usage in teaching methods. They may tend to speak slowly and deliberately to minority students with the intention of making them understand more clearly. This pattern of interaction may appear to be distasteful and even repugnant to second-generation students who are fluent in English. As one student remarked:

These professors assume that you don't understand certain things that are explained in class and tend to explain more to you or speak slowly to you. This makes you feel stupid and idiotic. I only speak English and I don't know why she did that. To me it seems offensive.

This student was offended at being treated as a slow-learner due to the false assumption that he was not familiar with the English language. This condescending attitude can be interpreted as being racist. Further, such attitudes explicitly draw out the power relationship between dominant faculty members and minority students and are consistent with Max Weber's premise of power and domination that is depicted in the social context of racism (Weber, 1922/1968). The power of faculty members over students in certain academic social situations is incontestable. But, the power-dynamic between dominant faculty and minority student is often exacerbated by overt or covert racism.

For instance, one student expressed frustration with the mono-cultural focus of education and commented how the professor's views of white privilege excluded students of colour. This student reported that in the discussion of critical whiteness theory, the professor did not realize that he was referring to white privilege as an "invisible knapsack" that white people carry around, placing them in a decisively advantageous position (Mclntosh, 1989). In an analysis of the content of his lecture, this mainstream professor did not decentre and deconstruct (Derrida, 1976) white privilege and how dominant privilege placed minority students at a disadvantage. Indeed, it was reported that he did not even acknowledge the presence and views of minority students in the class. The following student reports: 
This prof at one time was talking about critical whiteness theory and how whites gained whiteness easily. He didn't include the fact that not everybody in the class was white. Not everybody in the class would be able to do it. Not that I have had special privileges - but I have never had a problem not being white. That irritated me a bit and I felt let down.

This student felt excluded from a discussion of an anti-racist perspective of critical whiteness theory - a discussion that could have made her feel particularly involved and included. Critical whiteness theory appraises whiteness as a social construct that "attaches (unearned) privileges, opportunities, safety and status to whites at the expense of people of colour" (Ellsworth, 1997, p. 266). This South Asian student was therefore a part of what Ellsworth calls the "double bind of whiteness" in an academic situation which can "confuse and paralyze, insuring repetitious performances of whiteness that (unintentionally, unconsciously) reiterate its racist work in academe and other educational contexts" (p. 268). This student experienced racism through the double bind of whiteness by a professor who apparently critiqued whiteness but who, at the same time, unintentionally imposed his whiteness on students of colour.

Some minority students professed that dominant professors do not understand the struggles and burdens that are borne by the peoples of developing countries. This minority student relayed the discomfort and unease she faced in class when mainstream professors discussed third world issues with the intention of making minority students feel comfortable in class - but instead only made matters worse by singling her out and asking her opinion and views on the topic.

Every single professor who has taught me is white and I don't think we think the same. They don't understand the struggles and the burdens we bear. When a third world issue is discussed I have to contribute and explain to the whole class. The professors act like they want to make you comfortable in the class but all they are doing is parade us in front of the whole class. I have to constantly represent my culture and educate the masses. That really makes me feel uncomfortable. 
This student, being the only person of colour in the class, felt constrained to explain third world issues to the rest of the class, whether or not she was knowledgeable about the topic. However, when the dominant faculty is European and mainstream, one can hypothesize that the course is more likely to center on Eurocentric subjects and examples because of the expertise of the faculty. Thus, diversity among faculty is needed for a balanced worldview and referentiality in courses.

Unlike majority students, minority students are sometimes "expected" by some dominant faculty members to represent their group. This second-generation student was unlikely to know enough about her country of origin in order to "educate the masses." She, therefore, felt she was put on the spot and made to feel uncomfortable and ill at ease. Patricia A. Monture (1995) expresses a similar sentiment, when a professor of law at Queen's University made stereotypical comments about Native Indian people and reveals her feelings candidly: "I had felt very exposed at having my personhood and my reality laid bare on the table in front of the people in class without my consent" (p. 271). Some dominant professors in positions of power and privilege are sometimes "blind" and callous to the pain they inflict on minority students.

South Asian students also expressed the view that minority interests are peripheral to mainstream discourse. Some professors did not see eyeto-eye with the selection of unconventional topics or those related to other cultures in essay writing by minority students. In this regard one student remarked:

This professor was not happy with my selection of topic [which was on a third world issue]. A housemate and I faced the same problem - the same condescending attitude. You go for help and you really never get it.

This student expressed the view that this professor was not helpful in terms of the selection of essay topics, treated her patronizingly and offered guidance that was not beneficial to her academic work. She also highlights a salient point that research related to the third world is generally not as valued as issues related to dominant themes.

Another example of differential treatment by faculty included giving more guidance to white students than students of colour about assignment 
formats. In such instances, preferential treatment to do better was perceived to be given to white students by dominant faculty. Such implicit messages of racial differentiation reinforced students' feeling of marginalization. As one science student, remarked:

Yes, definitely there are racist practices followed in guidance given about writing assignments. The professors don't tell you everything you need to know about writing an assignment and sometimes they try to confuse you and do not give clear-cut answers... So there is a difference in the way they guide white and minority students. Regarding questions also - more explanations are given to white students' questions than minority students.'

The student perceived racism in the professor's positive attitude towards white students and negative attitude towards minority students. He professed he felt belittled and humiliated in the process.

Again, an engineering student was of the opinion that some faculty members were unapproachable, aloof and standoffish and gave inadequate guidance to minority students. Very often students who are racially and culturally different find it difficult to approach professors because they are uncomfortable with the friendly and collegial style of interaction between mainstream faculty and mainstream students. Or, they may find the aloof style of the professor intimidating and daunting and not easily approachable.

Some professors are not easy to approach and I don't go into the office. I have not had much experience talking to professors. They are not easily approachable. They take their own time replying [to] your email and they don't give adequate guidance in projects.

A law student corroborated this view, adding that some professors were insensitive to the difficulties she was experiencing.

I don't think some professors are very approachable. I think the bigger problem for me is that personally, I feel more comfortable if they recognize at least some of the difficulties I am facing. It is clear that I cannot talk easily with certain professors. 
The aloofness and indifference of certain professors were explained in terms of lack of contact and interaction between faculty and science students in large classes. One science student narrated the following:

There is lack of adequate contact between the professor and the students. In the science classes it is rare that professors go out of their way to get to know the students. Because of the large classes in the sciences, there is limited interaction between the professors and the students. They should know that minority students have their own problems and their own ways of learning and that may sometimes need more help. But this is hardly the case.

This subject's comment about aloofness is consistent with PattersonStewart, Ritchie and Sanders' study (1997) that some dominant faculty "were visibly uncomfortable or inappropriate in their interactions with [minority] students" (p. 493).

Another computer science student remarked about the differential way group work presentations were evaluated by a professor, reinforcing racist attitudes in the university. She commented:

With regard to group work, this professor gave us the lowest marks though we had the best presentation. The whole class felt it. We were an ethnic group consisting of two South Asian and two Chinese students. The problem was to implement a software program. Our group maxed $95 \%$ while the other groups came up to only $25 \%$ of the implementation. But our group was marked the lowest and we felt that it was blatant racism. That was a terrible, terrible form of racism that was exhibited. Other groups got $90-97 \%$.

This computer science student who hesitantly narrated the incident was visibly moved when she recounted the incident. She was convinced that the incident reflected racist attitudes. She also commented that she did nothing about the incident and accepted the mark that was given to the group. This indicates that some minority students are apprehensive about reacting openly or complaining about racist experiences.

A medical student stated that she felt that she was picked on and grilled with more questions than mainstream students and professed that she felt humiliated and "tortured" by the procedure. In her words: 
I had a big problem with two of the preceptors in the second year. In clinical skills, held twice a week, where they make you practice taking history and physical examination skills in the hospitals on actors, I had a big problem with two of them, a man and a woman, of Caucasian background. They were awful, grilling you with questions till you can't answer any more. I felt that I got picked on, possibly because I belonged to a minority group - always asked to answer horrible questions, do extra things and present in front of the group. That irritated me. They had a horrible approach to teaching and were torturing (minority) students year after year.

This student perceived that she was singled out to answer more questions than other mainstream students. In this comment, power relations that are legitimated are evident in this student's interaction with the preceptors of the department. Not being able to do anything much about the situation or helplessness adds greater intensity to this form of oppression.

The Human Rights coordinator on campus who liaised between students and faculty and who was constantly alert to problems of racism on campus felt that many students were fearful of lodging any kind of complaint. Many bore perceived experiences of racism in silence.

I have heard a lot of complaints from my interaction with students on campus that some professors on campus are really mean and treat them shabbily. But most students don't want to speak about them nor complain. They just bear it silently because they belong to the minority group.

The above comment suggests that minority students rarely report incidents of racism and bear the brunt of racism "silently." This is likely due to the fear associated with repercussions that might ensue in the facultystudent dynamic. Among the interviewees, not a single student spoke of lodging a complaint with the Human Rights Office.

When students bear the brunt of the effects of perceived racism silently, their educational experience is diminished. Consistent with Patterson-Stewart et al. (1997) study, the thread that runs through the above participant's narratives is "how he or she had historically received powerful messages that [minority students] did not belong in White academe" (p. 491). 
Tinto's (1975) institutional-oriented theory asserts that greater levels of interaction between student and faculty lead to an increase in academic commitment to the university, thereby leading to students' persistence in studies. Factors that affect student persistence in universities relate to university experiences and academic performance. These experiences involve one's relationship with faculty, peers and staff and feelings of affirmation and belonging. Astin (1982) argues that minority students' positive feelings of fitting in culturally created a sense of feelings of affirmation and belonging and the desire to excel in university. However, this perception of fitting in socially and culturally is closely dependent upon congenial relationships with faculty, staff and peers in the university setting.

This student felt she did not culturally fit into the university milieu even though she was born in Canada. Relaying her feelings on the subject she states:

I don't think I am a cultural fit in this university. I know I don't fit in here even though I was born in Canada. So you really don't fit in here. This is because [white] faculty, peers and the culture around do not particularly accept me. I don't think that if you come from somewhere else you would feel particularly or hugely welcome also.

This student felt that she was not a cultural fit due to the tensions she faced in interactions with faculty. She professed she felt unwelcome and unaccepted due to her migrant status. Even though she had intentions of continuing her graduate education in the same university, she expressed these feelings of not fitting in culturally in the predominantly white university with emotion and poignancy. Gloria, Kurpius, Hamilton and Willson (1999) discuss that "bicultural skills" (p. 263) are necessary to successfully negotiate spaces in white university settings.

Dei et al. (1997) in their ethnographic study of Black students' disengagement from school affirm that, "teachers... are an important factor with regard to student engagement" (p. 78). Likewise, Defour and Hirsch (1990) found that along with the power dynamics that exists between dominant faculty and minority students, among African American graduate students, including those in medicine and law, more 
out-of-class contact with African American faculty and students resulted in greater attrition rates. Further, African American students who had developed informal relationships with mentors or faculty were more inclined to succeed academically than those who did not (Hackett \& Byars, 1996; Terrenzini, Pascarella \& Lorang, 1982).

Even though the Black student's experience of racism can be more intense, severe and extreme the differential experience of South Asian students is analogous. In this study a graduate science student remarks:

My professor and I don't enjoy the same kind of interpersonal relationship that I had with my professor back home in India. $\mathrm{He}$ is very businesslike and abrupt. There is no informal, out-of-class contact with him at all and I had a stressful relationship with him because of this.

This subject's comment suggests that a lack of informal contact with minority students outside class can lead to a stressful relationship with dominant faculty and affect academic progress. As Brown and Kurpius (1997) maintain: "The more informal contact a student has with faculty, the greater the chance that faculty will affect the students' academic development" (p. 5). Griffin (1992) agrees that informal interactions with faculty influence students' academic integration and persistence level.

As well, Carl Weiss (1981) has found informal interaction with faculty is crucial in acquiring a professional role commitment particularly for graduate students. While South Asian students might be able to maintain a certain level of formal interaction with faculty it is in the area of informal relations that they fall short because cultural norms are dissimilar in appropriately socializing with dominant faculty. For example, many of the interviewees do not partake in alcohol, are vegetarians, do not play golf or hockey, and are not familiar with dominant cultural practices and mannerisms. A lack of informal interaction and professional friendship or easy collegiality with dominant faculty particularly for graduate students causes stress and angst in social relationships and possibly may lead to disavantage in gaining academic knowledge and a lowering of standards in their academic work. Most South Asian students are conditioned to respect their professors and not treat them in a casual, friendly manner. 
This attitude is often misperceived as arrogance or aloofness. Margolis and Romero (1998) point out:

For...students of colour, professionalization requires the adoption of attitudes and behaviour patterns that are antithetical to their culture of origin - requirements that make the path through school more problematic and perilous than it might be for a student who arrives equipped with the dominant forms of cultural capital (p. 9).

Often the process of professionalization requires the acceptance of norms and values that are in opposition to the minority student's beliefs and practices. The minority student is, therefore, perceived as lacking in cultural capital and placed in a disadvantageous position.

\section{TEACHING STYLES, GRADING AND TRACKING}

All 22 students recounted negative interactions with regard to teaching styles. Teaching styles are an important component of the educational process in engaging the interest of the students and fostering the learning process (Dei et al., 1997). What is critical is that problems related to teaching styles of faculty affect the academic performance and general atmosphere of the class in academe. Students of Arts courses found teaching that was perceived as ineffective and biased to be more of a concern. They felt that a perceived Eurocentric emphasis with a penchant towards Anglo-Saxon assumptions and premises made them feel excluded and marginalized in classroom situations. The following two students reported:

1. When examples are used with western connotations, then the minority students are left out and minority students don't understand and find it difficult to pick up.

2. I think a Eurocentric bias exists at the level of what is considered good scholarly thought. Especially in English and Film, political analysis is not considered as valid as literary analysis. Therefore, work that deals with racism in texts is often devalued. I think this is especially hard for people of colour, because for me it's really hard for me to analyze a text or theory "objectively" when it reeks of racism. 
These students' comments suggest that the Eurocentric emphasis and an unwillingness to discuss issues of race in academic discourse by some dominant faculty members could be described as trivializing and ideologically belittling minority students.

In grading, interviewees repeatedly professed that there was a possibility of instructor bias affecting the level of marks. The following South Asian student claims that it is difficult to gauge if she has received a fair mark or not. Marks are given confidentially and few students wish to compare or even discuss them with fellow students. Under these circumstances, it is difficult to say whether a student has been given an impartial mark.

It 's hard to say about marks. In the social sciences I have no idea, because our discipline is so subjective and people of different races and gender I know disagree with marks they have been given. So I don't know what it is due to. It is possible that I have been given a bad mark because I am a woman of colour.

This subject's comment suggests that for some students racism is perceived in relation to grading despite the element of confidentiality and perceived objectivity. This student also expressed the view that in the social sciences, where the essays are graded subjectively, instructor bias is more likely to creep in. Further, both gender and race might have been contributing factors in her receiving a low mark. As Margolis and Romero (1998) maintain, gender and race often are layered oppressions, which contribute to the underestimation of students' academic potential in a predominantly white university environment

Due to the element of confidentiality, the following two students were unaware if they had been given fair or unfair marks.

1. When people grade your essay, you really don't know if you got fair marks. I wouldn't know even if I were given marks that are unfair. Unless I myself feel that I deserve more marks than what was given. It is difficult to say.

2. Maybe they don't know you. How are you going to know? It is subjective and I have never compared my marks with others. You are dealing with people's minds. But you are 
obviously not going to eliminate bias. Most of the Teaching Assistants are white.

Even though marks are relative, mainstream instructors or teaching assistants may be biased in their marking procedures. Some students perceive that teaching assistants, sanctioned by mainstream professors, may be influenced by biased stereotypes in a racially hostile environment that underestimates the academic performance of students of colour.

Some South Asian students perceived that teaching assistants of the majority group who mark the assignments and examinations may be prejudiced. One student commented:

Some Teaching Assistants are hard markers and I feel they do not give the marks you deserve. They can find out that you are a South Asian or a minority from your name.

The following science student, who had his earlier schooling in South Asia, felt that his work patterns set him apart from his white peers. He indicated that the manner in which he worked caused him to be evaluated lower than mainstream students who were familiar and well versed with the system.

In science subjects the problem is not so much the subject matter as the way we work, which is different. The way we write, phrases we use, the way we organize material and things like that. That causes us to be evaluated differently.

Another student said the following about grading:

My evaluations and grading was also affected since I was originally from India. I received a $B$ plus average in my Master's degree, which did not get me immediate admission into the doctoral program. I felt I deserved an A grade. I had to wait for two years to get into the doctoral program and this was a sheer waste of my time and resources. Because I got a B plus I was evaluated low and I was not given a graduate fellowship or research assistantship. I was not even given any other type of funding in the form of research work with professors. I struggled through my master's program financially. I feel my race limited my ability to 
achieve maximum academic success. I feel a lot of anger and resentment within me about this.

This student echoes the argument of Roscigno and Ainsworth-Darnell (1999), who contend that along with the student's academic potential, teacher evaluations play a significant role in affecting the academic achievement of minority students. Gatekeepers (teachers) play an important task in ascribing upper class students with highbrow cultural capital $^{8}$ and with more assistance, attention, consideration and expectations (Lamont \& Lareau, 1988). Tracking or classifying students into groups (such as honours or general) is clearly an ideal example of relegation in the university setting. The following student expresses her views on tracking:

In my master's program I was assigned to a white professor as supervisor who did not know the area I was working on. She simply could not advise me on the topic because she did not understand some of the indigenous concepts. A lot of misunderstandings and unpleasantness grew between both of us. I could have avoided this if I was given an appropriate supervisor. She felt that I could work only in a clerical capacity in a college after graduation. I felt really humiliated.

This student's comment suggests that the 'tracking' process can be biased and flawed based on negative stereotypes regarding the potential of minority students. A deliberate lessening of minority student competence can undermine self-confidence and self-reliance.

At the university level, tracking provides differential access to the best scholarships, research opportunities, postdoctoral fellowships, and publishing opportunities, awards, as well as employment in prestigious institutions. Students may perceive racism in the way that some supervisors were under the erroneous supposition that minority students were still a "colonized" people and that it was their responsibility to place them in the "appropriate" occupational positions.

Thus, teaching styles, grading and tracking are three processes that lie beneath the achievement returns of minority students. Indeed, a substantial body of research on gatekeeping and tracking reveal race and class biases (Boykin, 1986; Dauber, Alexander \& Entwisle, 1996). 
Paradoxically, many American researchers have typically downplayed the potential influence of race and class in the micropolitical dynamics of the classroom. Farkas (1996), an exception, who studied teachers' decisions regarding basic classroom skills and orientations found some differences along race, class and gender lines with inferences affecting students' grades. It is possible that some minority students are not rewarded in the same way as their white counterparts in terms of academic success. As Roscignio and Ainsworth-Darnell (1999) point out:

If cultural capital is predicated, in part, on the social position of its possessor and consequential micropolitical processes, the subordinate racial status of [minorities] may limit their ability to convert cultural capital and educational resources into academic success. (p. 161)

Roscignio and Ainsworth-Darnell (1999) express the view that given the significance of the presence of cultural capital in a student's academic success, the minority student's disadvantaged racial status contributes to lowering his/her cultural capital and therefore his/her level of academic success. From the above comments, there is evidence to suggest that South Asian students were alert and acutely aware of the perception that there may be bias in teaching styles, grading and tracking followed by dominant faculty. Though some students felt that they were not sure if this was the case, others believed that due to their subordinate minority status there was racism permeating various facets of faculty-student interactions. As well, the power dynamic between faculty and student exacerbates and aggravates feelings of racism between the two groups.

\section{IMPLICATIONS AND CONCLUSION}

This study reveals the pervasive importance of faculty-student relationships in creating a positive learning environment. Faculty have the power to influence students' sense of identity and self-esteem and also their academic success. It is quite telling that in faculty-student interactions, all 22 South Asian minority students interviewed in this study, perceived or reported having experienced some covert or overt racism or marginalization, based on their race, colour, or ethnic origins. It is 
noteworthy that all 22 participants in the study reported to be deeply affected by their experiences, which often left them with feelings of unfulfillment, lack of accomplishment, and dissatisfaction with both themselves as well as academia.

This study shows that racism is perceived to pervade everyday university discourse, invading the academic classroom as well as the social, emotional and cultural ethos of minority students. South Asian students, like other minority students, are in a vulnerable position and are prone to be influenced by faculty members. Students' career and future ambitions seem to depend on their experiences at university and their interactions with the faculty.

Recommendations suggested by interviewees were that more minority faculty members be hired on the basis of merit on predominantly white university campuses in Canada, with the expectation that this would create important changes in curriculum, teaching styles and instruction, and in the social and cultural patterns of faculty-student interaction and attitudes. Minority students also wished to see more professors from visible and other minorities with whom they could identify and who could become positive role models. More minority faculty were seen to be necessary in order to reflect the present pluralistic reality of Canada. The students strongly felt that a more diverse faculty could broaden the curriculum to include a wider global perspective, making knowledge more meaningful for them and making them feel more comfortable and empowered.

Further, it was perceived that the existing complement of minority faculty members should be expanded to create a " critical mass" so that a supportive, affable, collegial and equitable atmosphere could be created. This was felt to be important to overcome the potential marginalization of visible minority faculty and students. It was also recommended by some students that more antiracism training be provided to faculty and staff about the multicultural, multilingual and multiracial face of Canadian society. As Haroon Siddiqui (2001), O.C. editorial page editor of The Toronto Star states: "There needs to be ongoing anti-racist training given to personnel at all levels to instruct them in equity and human rights issues." The above recommendations, if implemented, will effectively 
enhance the academic potential of South Asian as well as other students in Canadian Universities. The hiring of more visible minorities in the hallowed halls of academia will be a giant step in creating education equity, curricular reform and in making the university setting more representative of the pluralistic diversity of Canada.

\section{Notes}

1 We use the term "predominantly white university" to refer to an institution with a population that is largely Caucasian.

2 The Canadian Government's Federal Contractors' Program mandates the hiring of four target groups - women, visible minorities, the disabled and people with different sexual orientation.

3 Defining first and second-generation minority students is problematic. However, in this study, we define first generation as those who have migrated to Canada. The offspring of first-generation immigrants constitute the second-generation group. Some second-generation students in this study were born here and others accompanied their parents after having part of their education in countries of origin. International students come under the first-generation category. The first-generation minority students, generally, experience problems related to having their prior learning experience assessed, access to professions and trades and the "Canadian work experience." Other related problems are linked to accent, language proficiency, mannerisms and unfamiliarity with the Canadian educational system. Second-generation minority students are more prone to experiencing issues related to "identity and culture conflict." First generation minority students do not have any doubts about their sense of ethnic identity. For second-generation minority students, there is greater variation in the degree to which they continue to hold a clear south Asian ethnic identity. Both first and second-generation minority students may experience racism but in different degrees and forms.

4 Throughout the analysis, the terms "mainstream" or "dominant," in reference to society as a whole, faculty members or students, means the majority white people of British and/or French ethnic origin.

5 "South Asian identification" refers to students primarily from India, Pakistan, Bangla Desh and Sri Lanka. 
6 The "model minority myth" originated in the United States when media paid attention to success stories regarding "high family income, high educational attainment and low rates of deviance among Asian Americans" (Chan \& Wang; 1991, p. 44). However, the other side of the coin was ignored by the media denoting that "many Asian-American kids experience immense psychological stress when they cannot live up to the 'whiz kid' stereotype" (p. 45). These whiz kids endure ostracization and taunting that they are intellectual "nerds." Further teachers neglect to give them any kind of special help based on the notion that they are intelligent and bright (p. 45). Though the "model minority myth" was originally applied to Chinese and Japanese Americans, later on South Asian Americans, due to academic excellence, were also included in this category. In this study, all twenty-two interviewees reported that they excelled academically in their studies, but could have done better, had it not been for the barriers they faced in the university setting.

7 Parts of quotes have been underlined for added emphasis.

8 "Cultural capital" or societally valued knowledge, in this context, is termed as "high-brow" culture or cultural cues that are exhibited in higher socioeconomic status families and linked to a superior level of academic success. High brow cultural practices "include attending museums and taking extra curricular classes in dance, art, music and the like" (Ganzeboom, DeGraaf \& Robert, 1990).

\section{References}

Astin, A.A. (1982). Minorities in American education. San Francisco, CA: Jossey-Bass.

Aronowitz, S. (2000). The knowledge factory: Dismantling the corporate university and creating true higher learning. Boston. MA: Beacon Press.

Bock, M.T. (1997). The measure of professional productivity: Using student learning outcomes criteria. ASHE annual meeting paper.

Boykin, A.W. (1986). The triple quandary and the schooling of Afro-American children. In U. Neisser (Ed.), The school achievement of minority children: New perspectives (pp. 57-92). Hillsdale, NJ: Erlbaum. 
Brown, L., \& Kurpius, S.E.R. (1997). Psychological factors influencing academic persistence of American Indian college students. Journal of College Student Development, 38(1), 3-12.

Burney, S. (1989). Ways of seeing/knowing: The pedagogy of representation in Brechtian theatre. $\mathrm{PhD}$ dissertation. Toronto, $\mathrm{ON}$ : University of Toronto.

Burney, S. (2002). Brecht in the Basthi: Performance and meaning across borders. In B. Rasmussen \& A.-L. Ostern (Eds.), Playing betwixt and between: The idea dialogues 2001 (3-127). Burgen, Norway: Idea Publications.

Dauber, S.L., Alexander, K.L., \& Entwisle, D.R. (1996). Tracking and transitions through the middle grades. Channeling educational trajectories. Sociology of Education, 59, 237-246.

Defour, D.C., \& Hirsch, B.J. (1990). The adaptation of Black graduate students: A social network approach. American Journal of Community Psychology, 18, 487-503.

Dei, G., Mazzuca, J., Mclsaac, E., \& Zine, J. (1997). Reconstructing 'Dropout:' A critical ethnography of the dynamics of Black students' disengagement from schools. Toronto, ON: Toronto University Press.

Derrida, J. (1976). Of grammatology. Trans. Gayatri Spivak. Baltimore, MD: John UP.

Ellsworth, E. (1997). Double binds of whiteness. In M. Fine, L. Weis, L.C. Powell \& L. Mun Wong (Eds), Off-white: Readings on race, power and society (259-269). New York, NY: Routledge.

Farkas, G. (1996). Human capital or cultural capital? Ethnicity and poverty groups in an urban school district. New York, NY: Aldine de Gruter.

Foucault, M. (1973). The order of things. New York. NY: Random House Press.

Foucault, M. (1980). In C. Gordon (Ed.), Power/Knowledge: Selected interviews 1972-1977. Brighton: Harvester Press.

Ganzeboom, H.B., Degraaf, P.M., \& Robert, P. (1990). Cultural reproduction theory on socialist ground: Intergenerational transmission of inequalities in Hungary. Research in Social Stratification and Mobility, 9, 79-104. 
Gloria, A.M., Kurpius, S.E.R., Hamilton, K.D., \& Willson, M.S. (1999). African-American students' persistence at a predominantly white university: Influences of social support, university comfort and selfbeliefs. Journal of College Student Development, 40(3), 257-268.

Giroux, H. (1992). The politics of postmodernism: Rethinking the boundaries of race and ethnicity. Journal of Cultural and Urban Studies. I(1), 5-38.

Griffin, O.T. (1992). The impacts of academic and social integration for Black students in higher education. In. M. Lang \& C.A. Ford (Eds.), Strategies for retaining minority students in higher education (pp. 25-44). Springfield, IL: Charles C. Thomas.

Hackett, G., \& Byars, A.M. (1996). Social cognitive theory and the career development of African American women. Career Development Quarterly, 44, 332-340.

Hall, S. (1997). Representation: Cultural representations and signifying practices. London: Sage Publications.

Hall, B.L. Kulig, J.C., Thorpe, K., \& Pfeuti, L. (1998). Understanding and application of culturally diverse issues within university settings. The Canadian Journal of Higher Education, 29(1), 105-128.

Huffman, T.E. (1991). The experiences, perceptions and consequences of campus racisms among Northern Plains Indians. Journal of American Indian education, 30, 25-34.

James, C. (1997). Contradictory tensions in the experiences of African Canadians in a Faculty of Education with an access program. The Canadian Journal of Education, 22(2), 158-174.

Jenkins, M.M. (1983). Removing bias: Guidelines for facultystudent communication. Virginia: Speech Communication Association.

Lam, C. (1996). The green teacher. In D. Thiessen, N. Bascia \& I. Goodson (Eds), Making a difference: The lives and careers of racial minority immigrant teachers. Toronto, ON: Garamond Press.

Lamont, M., \& Lareau, A. (1988). Cultural capital: Allusions, gaps and glissandos in recent theoretical developments. Sociological Theory, 6, 153-168.

Maclear, K. (1994). The myth of the model minority: Rethinking the education of Asian Canadians. Our School/Our Selves, July, 54-76. 
Marcias, J.E. (1993). Forgotten history: Educational and social antecedents of high achievement among Asian immigrants to the United States. Curriculum Inquiry, 4, 409-432.

McIntosh, P. (1989). White privilege: Unpacking the invisible knapsack. Peace and Freedom, July/August, 17-19.

Monture-Okanee, P.A. (1995). Ka-Nin-Geh-Heh-Gah-E-Sa-NonhYah-Goh. In The Chilly Climate Collectives (Eds.), Breaking anonymity: The chilly climate for women faculty. Waterloo, ON: Wilfred Laurier University Press, pp. 265-278.

Moon, S.M., Dhillon, D.R., \& Sprenkle, D.H. (1990). Family therapy and qualitative research. Journal of Marital and Family Therapy, 16, 357-374.

Margolis E., \& Romero, M. (1998). The Department is very male, very white, very old and very conservative: The functioning of the hidden curriculum in graduated sociology departments. Harvard Educational Review, 68(1) Spring, 1-31.

Marshall, C., \& Rossman G.B. (1999). Designing qualitative research, third edition. Thousand Oaks, CA: Sage Publications.

Mukherjee, A. (1992). A house divided: Women of colour and American feminist theory. In C. Backhouse \& D. Falttery (Eds), Challenging times: The women's movement in Canada and the United States. Montreal, QC: McGill-Queen's University press.

Patterson-Stewart, K.E., Ritchie, M.H., \& Sanders, E.T.W. (1997). Interpersonal dynamics of African-American persistence in doctoral programs in predominantly white universities. Journal of College Student Development, Sept/Oct. 38(5), 489-498.

Pushkin, D.B., \& Colon-Gonsalez, M.H. (1998). Access to knowledge and critical thinking in general chemistry via social constructivism: Pedagogical and curricular opportunities for minority science majors. Paper presented in the 1998 AERA Annual Meeting, San Diego, CA, April 13-17. Special Interest Group: Education in Science and Technology.

Razack, S. (1995). The perils of talking about culture: Schooling research on South and East Asian students. Race, Class and Gender, 2(3), Spring, 67-82. 
Roscigno, V.J., \& Ainsworth-Darnell, J.W. (1999). Race, culturecapital and educational resources: Persistent inequalities and achievement returns. Sociology of Education, 72, July, 158-178.

Rushowy, K. (2000). U of T faculty: Where minorities are not very visible. Toronto Star, January 10.

Said, E. (1983). The world, the text, and the critic. Cambridge, MA: Harvard University Press.

Siddiqui, H. (2001). How prejudices manifest themselves in policecitizen relationships. Speech delivered at JDUC, Queen's University, June, 13, 2001.

Sperber, B., \& Wilson, D. (1986). Relevance: Cognition and communication. Cambridge, MA: Harvard University Press.

Spivak, G. (1990). Postcolonial critic: Interviews, strategies, dialogue. New York, NY: Routledge.

Statistics Canada (1996). Annual reports. http://www.statcan.ca/ English/census96/list.htm.

Steele, C. (1997). A threat in the air: How stereotypes shape intellectual identity and performance. American Psychologist, 52, 613-629.

Terrenzini, P., Pascarella, E., \& Lorang, W. (1982). An assessment of the academic and social influences on freshman year educational outcome. Review of Higher Education, 5, 86-110.

Tinto, V. (1975). Dropouts from higher education: Synthesis of recent research. Review of Educational Research, 45, 89-125.

Weber, W. (1968). Economy and society. (Translated by G. Roth \& C. Wittich, Eds.). New York, NY: Bedminster. (Original work published 1922).

Weiss, C. (1981). The development of professional role commitment among graduate students. Human Relations, 34, 89-125.

Young, T.R. (1974). Transforming sociology: The graduate student. American Sociologist, 9, 135-139. 